\title{
THE VISCOSITY EFFECT ON VELOCITY OF A MACROSCOPIC VEHICULAR TRAFFIC MODEL
}

\author{
Erick Javier Lopez-Sanchez ${ }^{1, *}$, Norma Yanet Sanchez-Torres ${ }^{2}$, Patricia Eugenia Olivera Martinez ${ }^{3}$ \\ ${ }^{1}$ Faculty of Philosophy and Letters, National Autonomous University of Mexico, Coyoacan, Mexico \\ ${ }^{2}$ Faculty of Sciences, National Autonomous University of Mexico, Coyoacan, Mexico \\ ${ }^{3}$ Critical Urban Studies Seminar, Geography Department, Faculty of Philosophy and Letters, National Autonomous \\ University of Mexico, Coyoacan, Mexico
}

*E-mail of corresponding author: lsej@ciencias.unam.mx

\section{Resume}

Traffic in Mexico City poses a serious problem of vehicle saturation that causes a decrease in speed and increased transport time in the streets that suffer mobility collapses. A macroscopic model of vehicular traffic is used to show the effect of viscosity on the vehicular variables (speed and vehicle density), applied to two avenues in Mexico City, is studied. The input parameters were calculated following the Greenberg model. As the original model presents numerical divergences, the two assumptions corresponding to conservation of the vehicle's mass and the viscous term are modified. The results suggest that the viscosity depends on time and that it can be adapted to recommend modifications in urban mobility parameters, or even to implement the public planning policies in construction of infrastructure for urban transport, to make vehicle flow more efficient.

\section{Article info}

Received 15 May 2020

Accepted 11 August 2020

Online 18 December 2020

\section{Keywords:}

Greenberg traffic model, viscosity, vehicular density, vehicular velocity, numerical simulations

\section{Introduction}

Transport is a part of the urbanization process produced within a host of intentions, such as real estate, residential developments, productive location and points of commerce in its various formats. The transport is implicit to any of them and together they continually reorganize the urban spaces, forming and destroying networks of exchange of these activities. The transport role is very significant for organization of urban spatiality since transport systems in large metropolises are essential for labor and student mobility, circulation of goods, delivery of services, and many other reasons in the productive and social spheres. According to the differential intensities of local, intrametropolitan, and even regional scales, the transport saturation derived from vehicular flows and vehicular densities generates frequent problems of mobility.

Time plays a critical role, jointly mobility is associated with transport efficiency. The traffic volume also responds to a group of elements, such as increases in population density, structure of the hierarchical road map, routes of means of transport and their connectivity, mass of circulating vehicles and the transport hubs that are configured in the metropolis by the origin-destination concentrations. Vehicular traffic is studied over the world because of increase of the mobility generalized problems. Most of the studies are centered in the vehicular flow, in which they relate the vehicular speed and the density of the traffic.

Vehicular traffic models have been developed since 1935. From measured data of speed, vehicular flow and vehicular density using a $16 \mathrm{~mm}$ simplex movie camera to take pictures and an electric motor driven by an automobile storage battery operated the camera with a constant time interval between exposures, Greenshields [1] deduced one of the first traffic models. Later, Lighthill and Whitman [2] and Richards [3] built their model based on the advection equation. Macroscopic traffic models were made based on the Navier-Stokes and continuity equations, for example, the Greenberg model [4], Newell model [5], Paveri-Fontana model [6], Helbing model [7], among others [8-16]. A genealogy of traffic models has been described by van Wageningen-Kessels et al. [17].

Most of these models are validated in segments of streets or avenues in which they do not have intermediate entries or exits of vehicles, i. e. the number of cars that enter from one side of the road, is the same as the one that leaves from the other side. In that sense, there is a conservation of mass. However, most vehicular roads do not have that property. Some streets end in avenues, while there are streets that interconnect with other ones. In this aspect, there is no necessarily a mass conservation. For instance, the Greenberg model is based on the fundamental equations of fluid mechanics, assuming that the vehicle 
flow is compressible. Greenberg's data match with his model because they referred to the extreme sides of the Lincoln tunnel under the Hudson River, which divides New Jersey from New York. In this place, there is no possibility of an intersecting street. Greenberg proposes that speed is a function of vehicle density, which simplifies the equations for the analytical solution.

On the other hand, vehicular traffic in Mexico City entails serious challenges due to saturation, conflicting nodes, intermittent connectivity, because the transport demand is greater than the transport offer and the growing vehicle park, all of them causing the drop-in velocity. Because of the traffic saturation, travel time increases gradually. According to travel costs, collective public transport does not raise tariffs, but private transport expenditures augment, as well for transport companies.

In the Metropolitan Area of Mexico City (ZMCM) in 2017 , there were $34,558,217$ trips per day, within the urban area of 214,791 hectares [18]. In 1994 there were 20,573,700 trips per day [19], that is, these increased by more than 608,000 trips per year. In Mexico City, the average travel distance is $20.9 \mathrm{~km}$. The mean speed of all the kinds of transport has fallen from $38.5 \mathrm{~km} \mathrm{~h}^{-1}$ in 1990 to $13.8 \mathrm{~km}$ $\mathrm{h}^{-1}$ in 2017 [20]. The average speed of a bus is $8.8 \mathrm{~km} \mathrm{~h}^{-1}$, the mean velocity in the metro is $21.1 \mathrm{~km} \mathrm{~h}^{-1}$, in express transport (Metrobus) is $13.9 \mathrm{~km} \mathrm{~h}^{-1}$. The average travel time is 90.6 minutes and it continues to increase [21]. The vehicular speed between the origin and destination points are decreasing slowly [22].

The problems that aggravate the road congestion in the ZMCM are associated with the growing private fleet. In 2017 it reached more than 6 million vehicles [18], the private only mobilize $30 \%$ of total trips, and the concessional has a low capacity of transportation [21]. The urban layout and the continuity of the primary roads are interrupted because of the conurbation of more than 145 native towns. With immigrants from the whole country, these old towns grew rapidly conserving a very narrow road network.

In this paper, a modified Greenberg model is used, which considers the loss or gain of vehicular mass in the selected road segment with intermediate inputs and outputs [23-25], and the viscosity term to the motion equation, to simulate the traffic variables in two cases. The viscosity is interpreted as the high-grade driver anticipation [26].

The model is solved completely using a numerical method. The initial and boundary conditions (Dirichlet conditions [27-29]) of the traffic model are measured data about speed, vehicular density and vehicular flow that has been taken at peak hours, registered for 3 hours in a working day in two roads of Mexico City.

The objective of this work was to study the effect of viscosity on the traffic variables by simulating with a modified Greenberg model, using measured data of the traffic variables as the initial and boundary conditions. Simulations are carried out to observe behavior of the traffic variables in the entire domain when the viscosity varies. The viscosity is important because it can relate to urban mobility parameters.
The work is organized as follows. The data collection methodology is shown in section 3. The modified traffic model is presented in a general way in section 2 . The places of observation and data collection in Mexico City, as well as the data analysis, are shown in section 4. Section 3.2 contains the numerical method used to solve the system of partial differential equations of the traffic model and the numerical results are presented in section 5. Finally, a summary is presented in section 6 .

\section{Theoretical framework}

\subsection{The Greenberg model}

Greenberg built his model from the one-dimensional motion of a fluid equation [30]:

$\frac{D u}{D t}=-\frac{c^{2}}{k} \frac{\partial k}{\partial x}$

where $u$ : traffic velocity, km per hour, $k$ : density of traffic, vehicles per $\mathrm{km} ; x$ : distance along the road, $t$ : time, $c$ : a parameter that is determined from the state of the fluid and $D / D t=\partial / \partial t+u \partial / \partial x$ is the material derivative.

The continuity equation is written as:

$$
\frac{\partial k}{\partial t}+\frac{\partial q}{\partial x}=0
$$

Here $q=u k$ is the traffic flow [vehicles per hour], it represents the flow rate in fluids. All of them are functions of the position $x$ and the time $t$ :

$q(x, t)=u(x, t) k(x, t)$.

The Greenberg's model [4] has a significant assumption, which is demonstrated that it was not always satisfied. That supposition is the velocity depends on the density $u=u(k)$, and then the system Equations (1) and (2) becomes the following equation ${ }^{1}$ :

$$
\frac{d u}{d k}=-\frac{c}{k}
$$

The solution of Equation (4) is

$u(k)=c \ln \left(\frac{k_{j a m}}{k}\right)$,

where $k_{\text {jam }}$ is the density for the traffic jam $(u=0)$. That means the density as a function of the velocity has the form:

$k(u)=k_{0} e^{-u / c}$.

\subsection{Viscosity in the traffic}

Equation (1) contains terms that are interpreted as actions concerning drivers: the nonlinear term $(u \partial u / \partial x)$ is the convection and it represents changes of the average

${ }^{1}$ see [4] for details. 
speed in a very small cell due to vehicles entering with different speeds; the pressure term $\left(c^{2} k^{-1} \partial k / \partial x\right)$ is the anticipation, that is, changes in speed due to anticipation of drivers in traffic conditions later on [26]. In this case, the pressure is directly proportional to the density $\left(P=c^{2} k\right)$, since the vehicular flow is assumed to be an ideal gas [24]. In this work, the viscous term is added as a pressure for which the speed changes with respect to the position:

$$
P=c^{2} k-\eta \frac{\partial u}{\partial x}
$$

The viscosity term in the acceleration equation is represented by the diffusive term in the traffic system. The speed diffusion is useful to improve the numerical properties of a model. Besides that, it helps to investigate the effects of numerical diffusion, which are unavoidable when numerically integrating macroscopic models [31]. The modified Greenberg model is:

$$
\begin{aligned}
& \frac{\partial u}{\partial t}+u \frac{\partial u}{\partial x}=-\frac{c^{2}}{k} \frac{\partial k}{\partial x}+\frac{\eta}{k} \frac{\partial^{2} u}{\partial x^{2}}, \\
& \frac{\partial k}{\partial t}+\frac{\partial q}{\partial x}=f(t),
\end{aligned}
$$

where $\eta$ is the viscosity $\left[\mathrm{km} \mathrm{h}^{-1}\right]$ and $f(t)$ must be proposed, estimated, or measured from the observational data.

The viscosity term can represent the driver's anticipation against any event [26]. If $\delta_{v}$ is the visibility distance (the distance at which the driver detects the eventuality: a person crossing the street, a bottleneck, a car slowing down, etc.) and $\tau_{a}$ the anticipation time, i.e. the time that the driver takes to prevent a crash, then one can define the viscosity as:

$\eta=\frac{\delta_{v}}{\tau_{a}}$

\section{$3 \quad$ Methodology}

\subsection{Data collection}

Once the observation points are chosen, the traffic variables involved in the model are measured, namely, speed $u$, density $k$ and capacity $q$. The speed is measured by fixing the two points on the road and observing the time that the vehicles spend to travel the distance between them. Subsequently, the distance between these two points is measured. With this, the average speed is calculated.

To measure the flow rate, vehicles passing through a fixed point in the road for one minute were counted. The number of vehicles per hour is estimated by multiplying the quantity measured by 60 .

The density was measured by counting the number of vehicles in the segment between the points that were set to measure the speed. Thus, the number of vehicles per unit of distance was obtained. With a simple proportional relationship, the number of vehicles per $\mathrm{km}$ is determined.

These measurements were made every $10 \mathrm{~min}$ for approximately $3 \mathrm{~h}$. To obtain an estimate of the intermediate points among the measured data (where no measurements were taken), a cubic spline interpolation was carried out with each variable. The interpolated data were entered as input values in the model. Thus, the known values of the variables at the borders (Dirichlet conditions [27-29]) were obtained.

The model is solved by the finite difference method in combination with an iterative method [32-33]. The details are shown in section 3.2 .

\subsection{Numerical method}

The system of the Equations (8)-(9) was solved numerically using the second-order finite differences method, backward for time and centered for position. The method convergence was evaluated increasing the number of mesh points. The mesh refinement finished when the solution was practically the same between the two consecutive refinements. The initial and boundary conditions were taken from the measured data. There was no assumption that velocity depends on density, as Greenberg did it (see section 2), the system of Equations (8)-(9) was solved as a whole. The solutions convergence was verified through the Courant number, defined as [24, 34]:

$C o=|u| \frac{\Delta t}{\Delta x}$.

If this non-dimensional number is lower than 1 , then the solution converges.

The functions $k(0, t), k(l, t), u(0, t)$ and $u(l, t)$ (where $l$ is the end of the line) were measured in discrete values, and $f(t)$ was calculated with those discrete values (see section $5)$. Then, all these functions have discrete domains. The cubic spline method was used to calculate the intermediate points and matching with the numerical meshes.

The numerical code was written in Matlab-script.

\section{Observational traffic data}

The observational data were obtained at two places in Mexico City, in a major avenue: Insurgentes at South of the city and Mexico-Toluca freeway atn the western city entrance. These ways were chosen because they had a few lateral inners and exits, so that the function $f$ should be very close to zero, but this was not quite possible.

\subsection{Insurgentes Sur Ave}

Figure 1 shows the first road section of the collected traffic data. This record was made on November 21, 2018. The variables $u(x, t), k(x, t)$ and $q(x, t)$ were taken for three and a half hours at two points. An observer was collocated in a pedestrian bridge at South (point 1), and the other one was placed on a pedestrian bridge at the North (point 2 ).

The measured flow's direction is South-North, so the input is at $\mathbf{1}$ and the output is at $\mathbf{2}$. The measurements were 


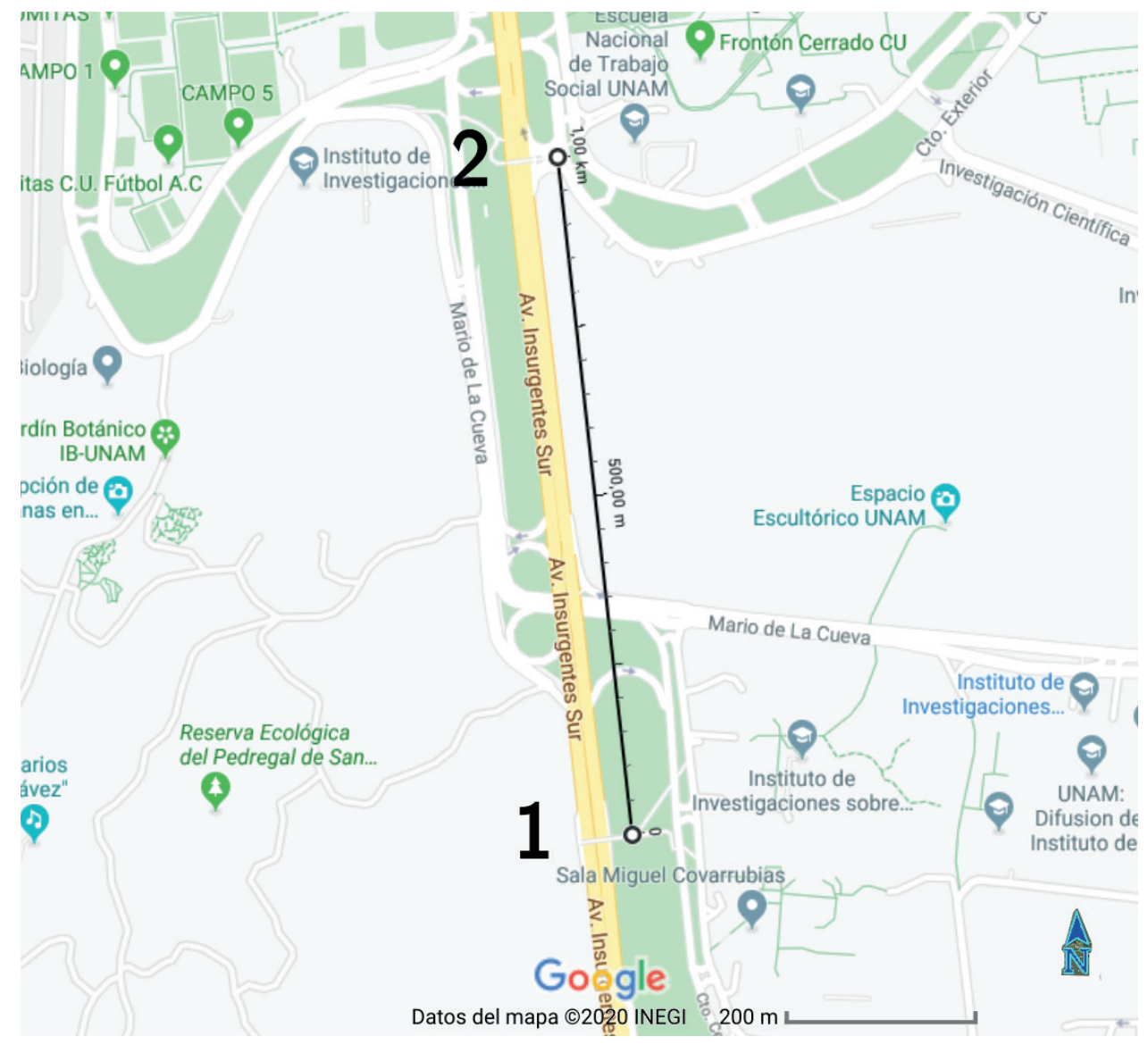

Figure 1 Insurgentes Sur, Mexico City, taken from Google Earth Pro 2018
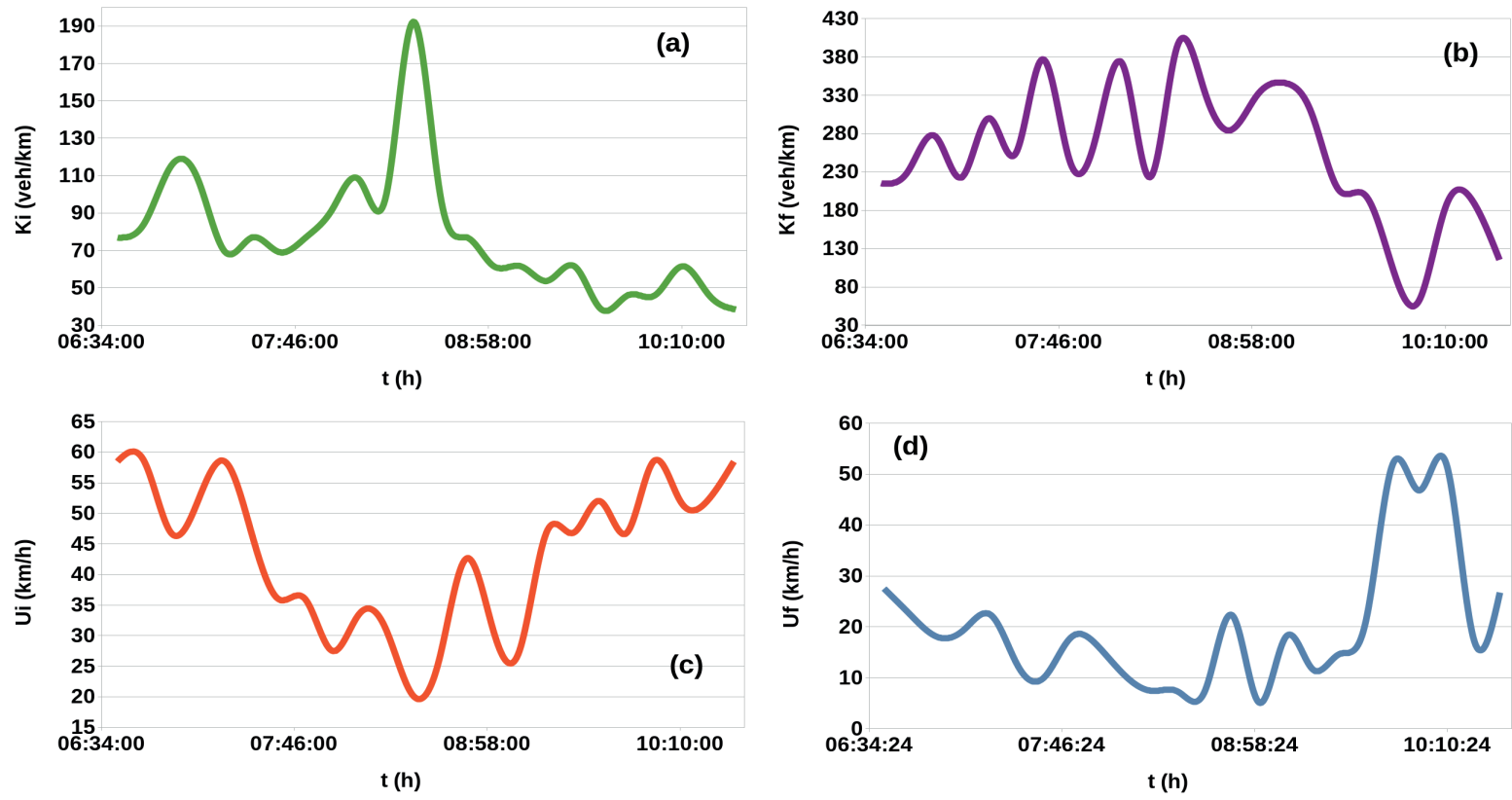

Figure 2 (a) Density of traffic at point 1, (b) Density of traffic at point 2, (c) Velocity of traffic at point $\mathbf{1}$,

(d) Velocity of traffic at point 2 , see Figure 1

made from $6: 40 \mathrm{hrs}$ to $10: 20 \mathrm{~h}$. One can see that there is a big vehicle exit-entrance at $350 \mathrm{~m}$ from 1 and another small vehicle's entry at $200 \mathrm{~m}$ from 1 . In this case, $\Delta x \approx 1 \mathrm{~km}$ and $\Delta t=10 \mathrm{~min}$, i. e. $\Delta t=1 / 6 \mathrm{~h}$.

One can see in Figure 2 that the density and velocity of traffic have a qualitatively opposite behavior, as
Greenberg's prediction says. One also can compare the measured traffic flow $\bar{Q}_{\text {measured }}$ and the calculated traffic flow $\bar{Q}_{\text {calculated }}=\bar{k}_{\text {measured }} \times \bar{u}_{\text {measured }}$, where the bar means "the average of." Even though the slope of the straight line is close to 1 , the linear regression shows a weak correlation between $\bar{Q}_{\text {measured }}$ and $\bar{Q}_{\text {calculated }}\left(R^{2}=0.28\right.$ Figure 3$)$. 


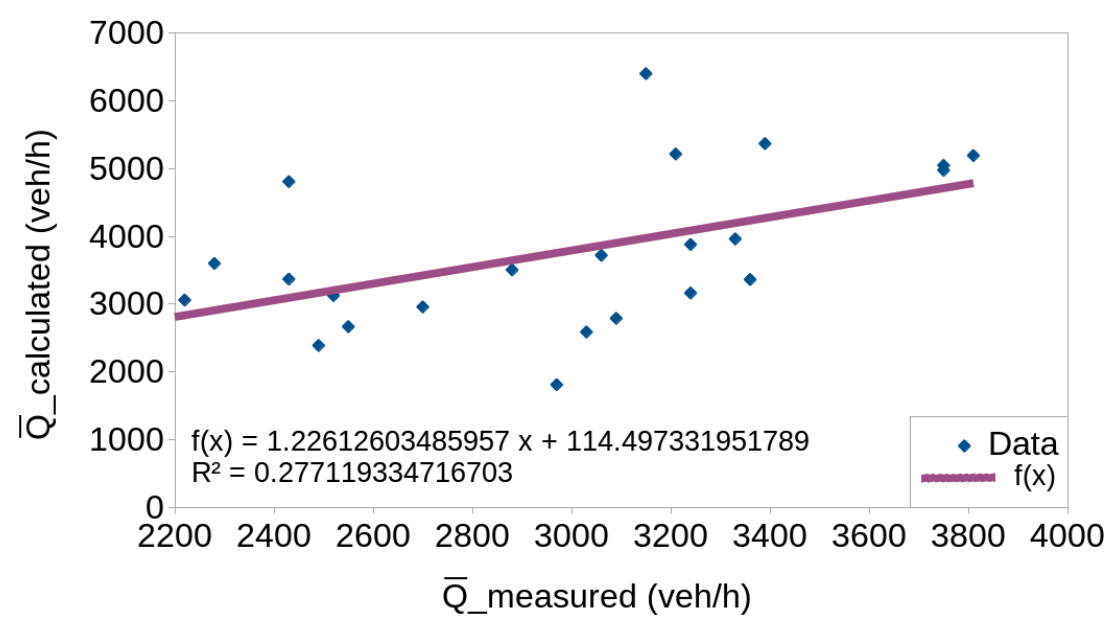

Figure 3 Relation between the calculated traffic flow and the measured traffic flow for the Insurgentes Sur case

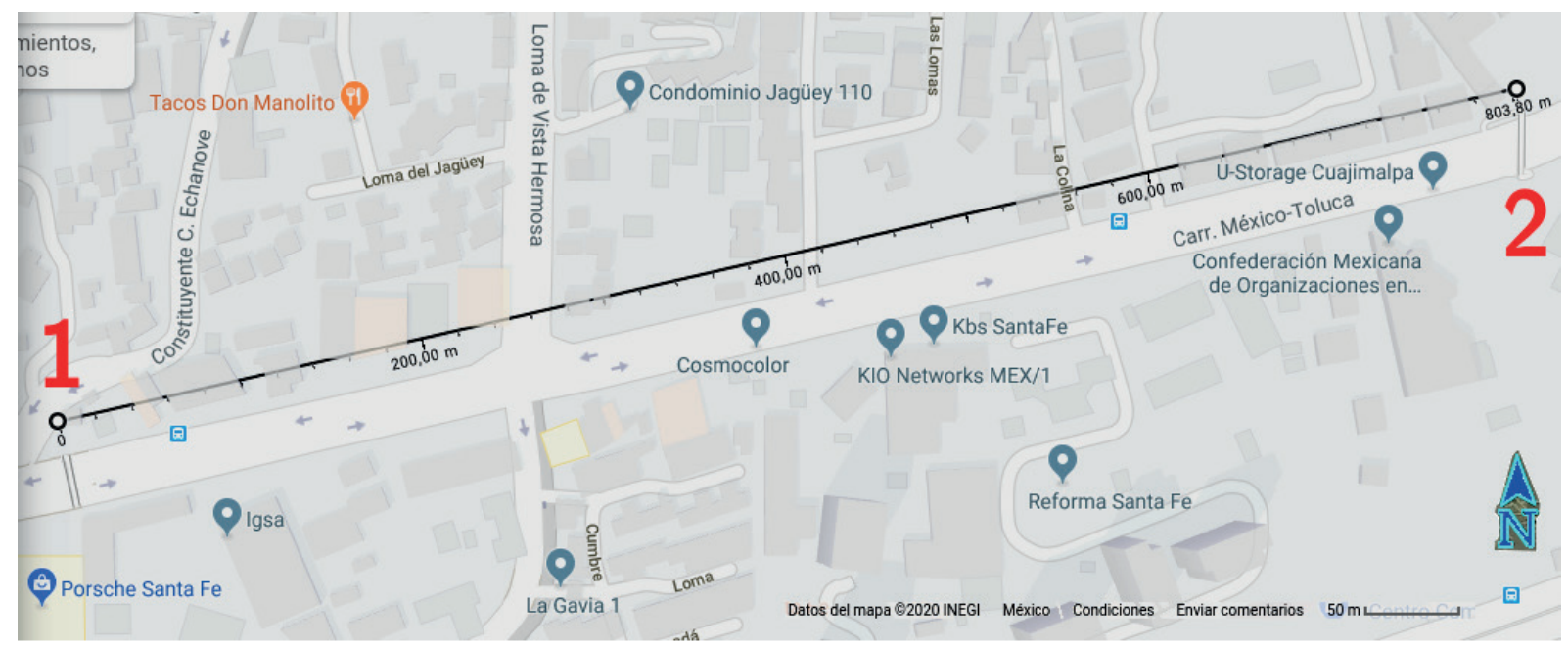

Figure 4 Mexico-Toluca Federal road, Mexico City, taken from Google Earth Pro 2018
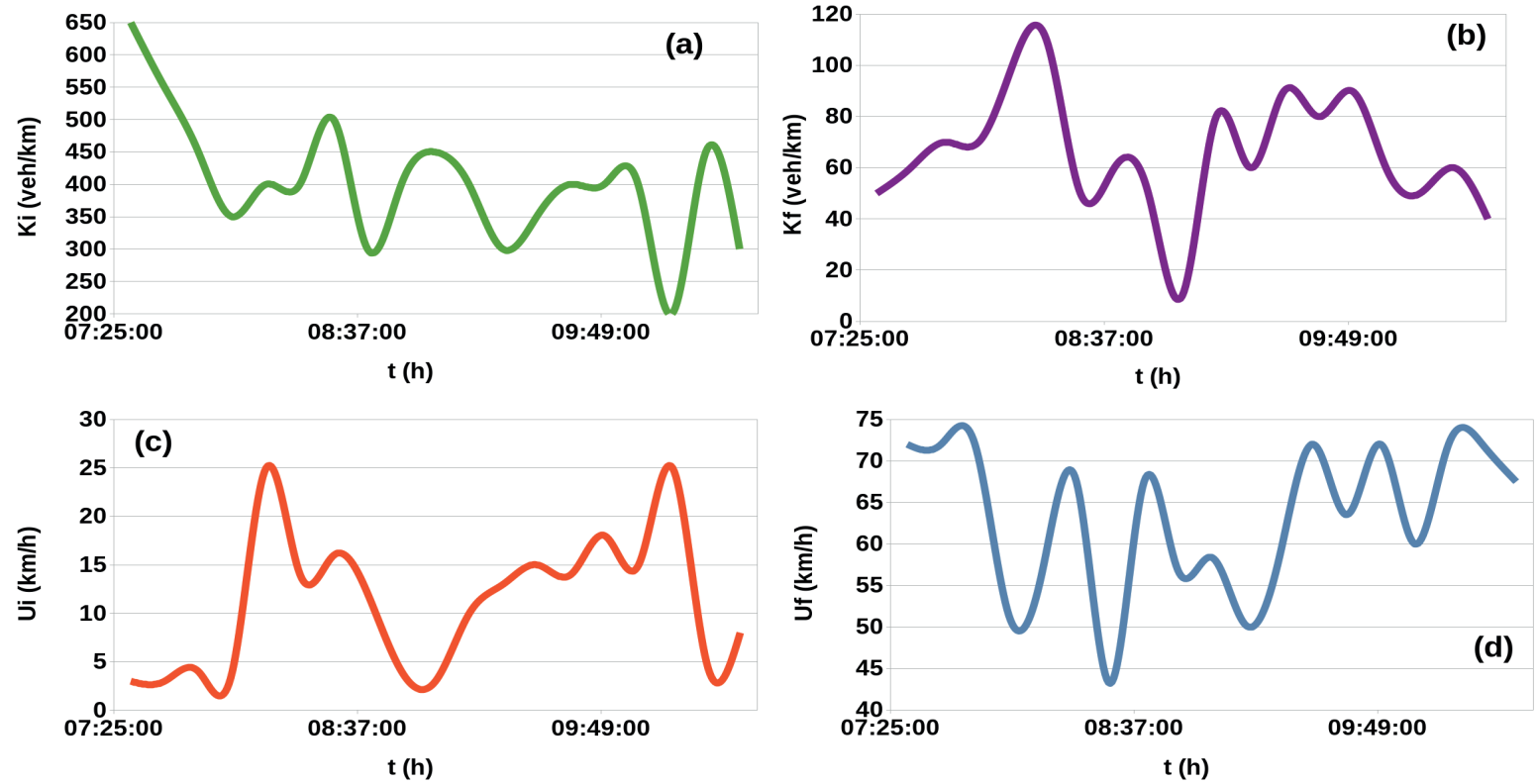

Figure 5 (a) Density of traffic at point 1, (b) Density of traffic at point 2, (c) Velocity of traffic at point 1, (d) Velocity of traffic at point 2 
Table 1 Some combinations of anticipation distance, time and viscosity (Equation (10))

\begin{tabular}{ccc}
\hline$\delta_{v}(\mathrm{~m})$ & $\tau_{a}(\mathrm{~s})$ & $\eta\left(\mathrm{km} \mathrm{h}^{-1}\right)$ \\
\hline 250 & 1.5 & 600 \\
500 & 4 & 450 \\
290 & 2.75 & 380 \\
210 & 3.4 & 220 \\
100 & 3.6 & 100 \\
50 & 9 & 20 \\
\hline
\end{tabular}

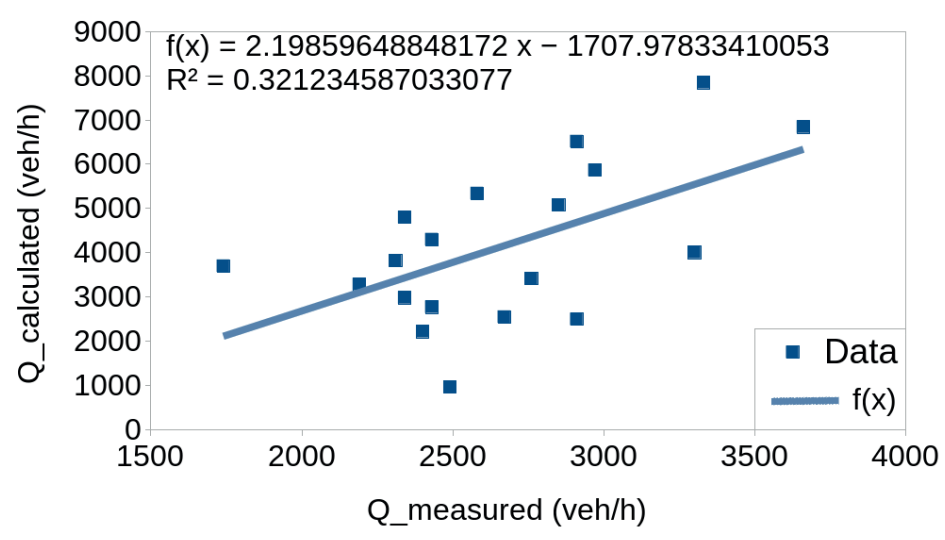

Figure 6 Relation between the calculated traffic flow and the measured traffic flow for the Mexico-Toluca case
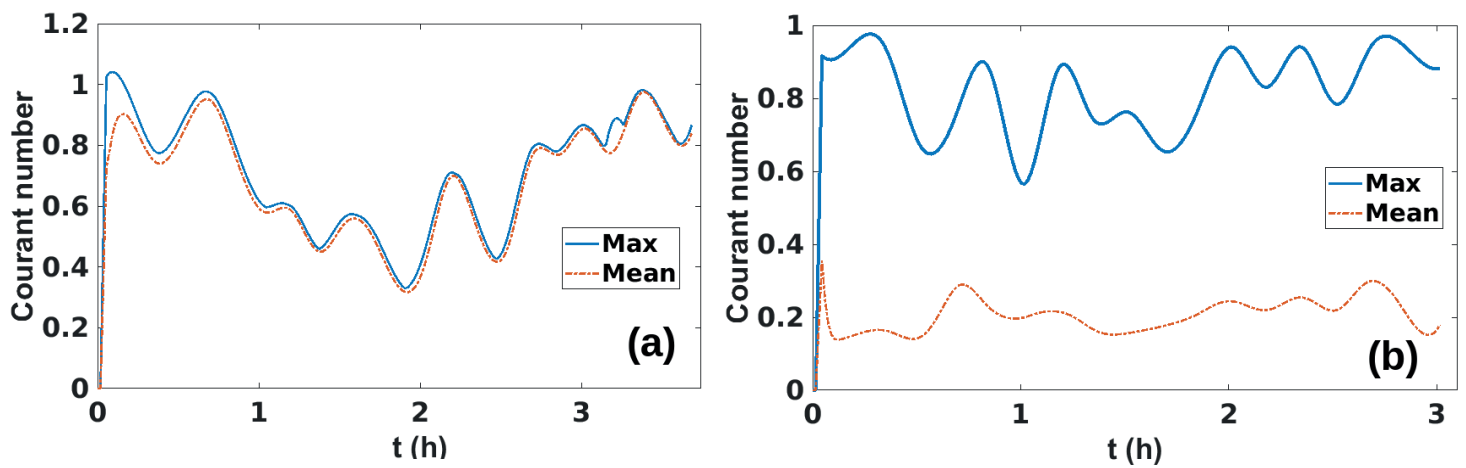

Figure 7 Courant number, $\eta=600 \mathrm{~km} \mathrm{~h}^{-1}$, (a) for the Insurgentes Sur case, (b) for the Mexico-Toluca case

\subsection{Mexico-Toluca free road}

Figure 4 shows the second road section of the traffic data collection. This record was made on November 13 , 2018. The variables $u(x, t), k(x, t)$ and $q(x, t)$ were taken for three hours at two points. An observer was placed on a pedestrian bridge at West (point $\mathbf{1}$ ) and the other was put in a pedestrian bridge at East (point 2).

The measured flow's direction is West-East, so the input is $\mathbf{1}$ and the output is $\mathbf{2}$. The measures were taken from $7: 30 \mathrm{~h}$ to $10: 30 \mathrm{~h}$. One can observe that there is an important vehicle exit at $250 \mathrm{~m}$ from 1 . In this case, $\Delta x \approx 0.8 \mathrm{~km}$ and $\Delta t=1 / 6 \mathrm{~h}$.

In Figure 5, one can see a contrary behavior of density and velocity too, but it is not as evident as in Figure 2. In the same way as in the Insurgentes Sur case, one can compare the measured traffic flow $\bar{Q}_{\text {measured }}$ and the calculated traffic flow $\bar{Q}_{\text {calculated }}$ (see Figure 6). In this case, the slope of the straight line is greater than 2 , besides the linear regression shows a weak correlation between $\bar{Q}_{\text {measured }}$ and $\bar{Q}_{\text {calculated }}$ $\left(R^{2}=0.32\right)$.

\section{Numerical results}

Numerical results are presented as the threedimensional graphs of variables $u(x, t)$ and $k(x, t)$. In addition, a time series of those variables are shown in two-dimensional graphs, which are presented at different values of fixed positions. Finally, the space-phase (known as "fundamental diagram" [17, 31, 35-36]) is presented for combinations of the three variables: $u, k$ and $q$. The calculations were carried out varying the parameter $\eta$, which took the values: 


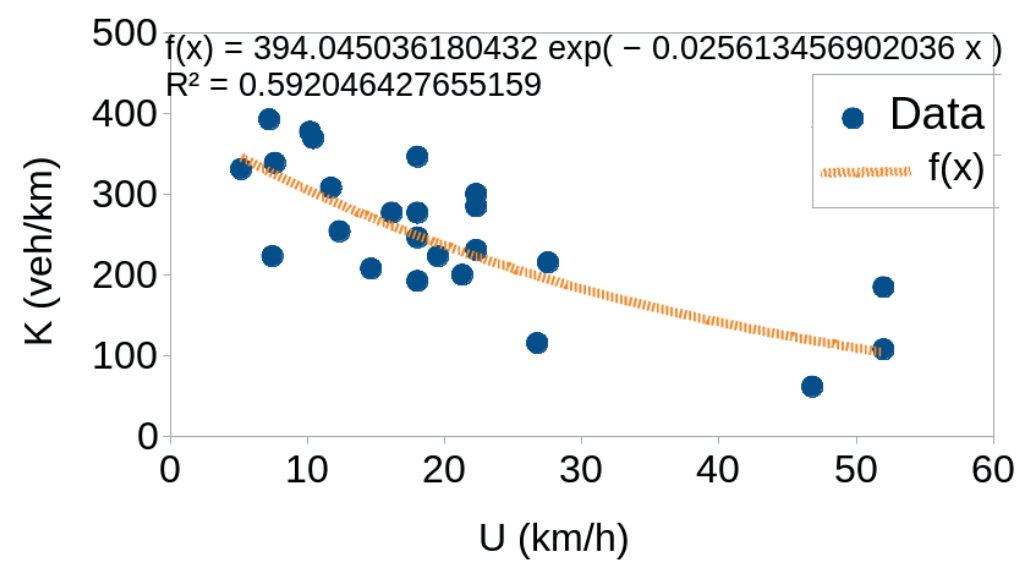

Figure 8 Phase portrait of the density and the velocity for the Insurgentes Sur case

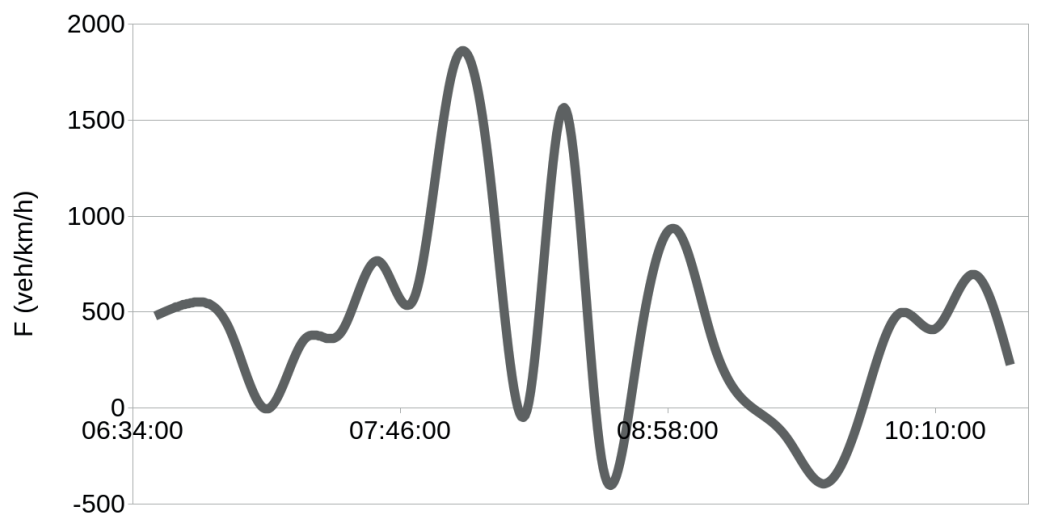

$\mathrm{t}(\mathrm{h})$

Figure 9 Function of the continuity equation for the Insurgentes Sur Ave
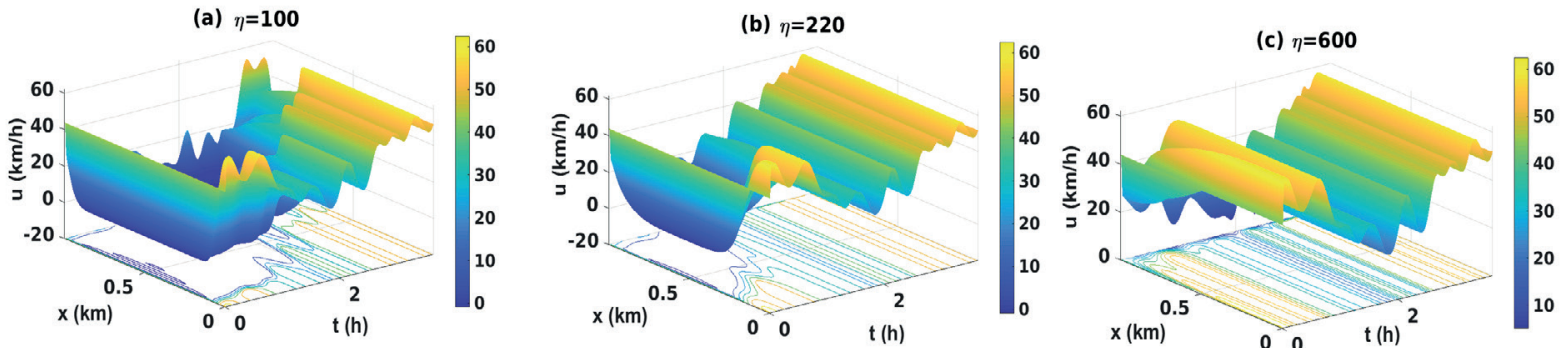

Figure 10 Velocity as a function of $x$ and t for the Insurgentes Sur case,

(a) $\eta=100 \mathrm{~km} \mathrm{~h}^{-1}$, (b) $\eta=220 \mathrm{~km} \mathrm{~h}^{-1}$, (c) $\eta=600 \mathrm{~km} \mathrm{~h}^{-1}$

$\eta \in\{0,1,5,10,20,50,100,220,380,450,600\} \mathrm{km} \mathrm{h}^{-1}$.

These values were defined based on the KernerKonhauser fundamental diagram [37-38], who have reported the value of $\eta=600 \mathrm{~km} \mathrm{~h}^{-1}$.

Table 1 shows several combinations of the visibility distance and the anticipation time to get various values of the viscosity.

To see the convergence of the solutions, the behavior of the Courant number in terms of time is shown in Figure 7. In Figure 7(a), the Courant number is greater than 1 only at the beginning, but its values become lower than 1 for the rest of the time. In the Mexico Toluca case (see Figure 7(a)), the Courant number is always lower than 1 all the time, therefore the numerical method is stable in both cases.
Function $f$ of the non-homogeneous continuity equation (Equation (9)) was calculated as follow:

$$
f(t) \approx \frac{\Delta k}{\Delta t}+\frac{\Delta q}{\Delta x}
$$

with $\Delta k=k_{2}(t)-k_{1}(t)$ and $\Delta q=q_{2}(t)-q_{1}(t)$ (see Figures 1 and 4$)$.

\subsection{Numerical results for Insurgentes Sur Avenue}

Insurgentes Sur is a 2-lane road for private vehicles and one lane confined to public transport service. If one estimates the number of vehicles in the case of traffic jams, 


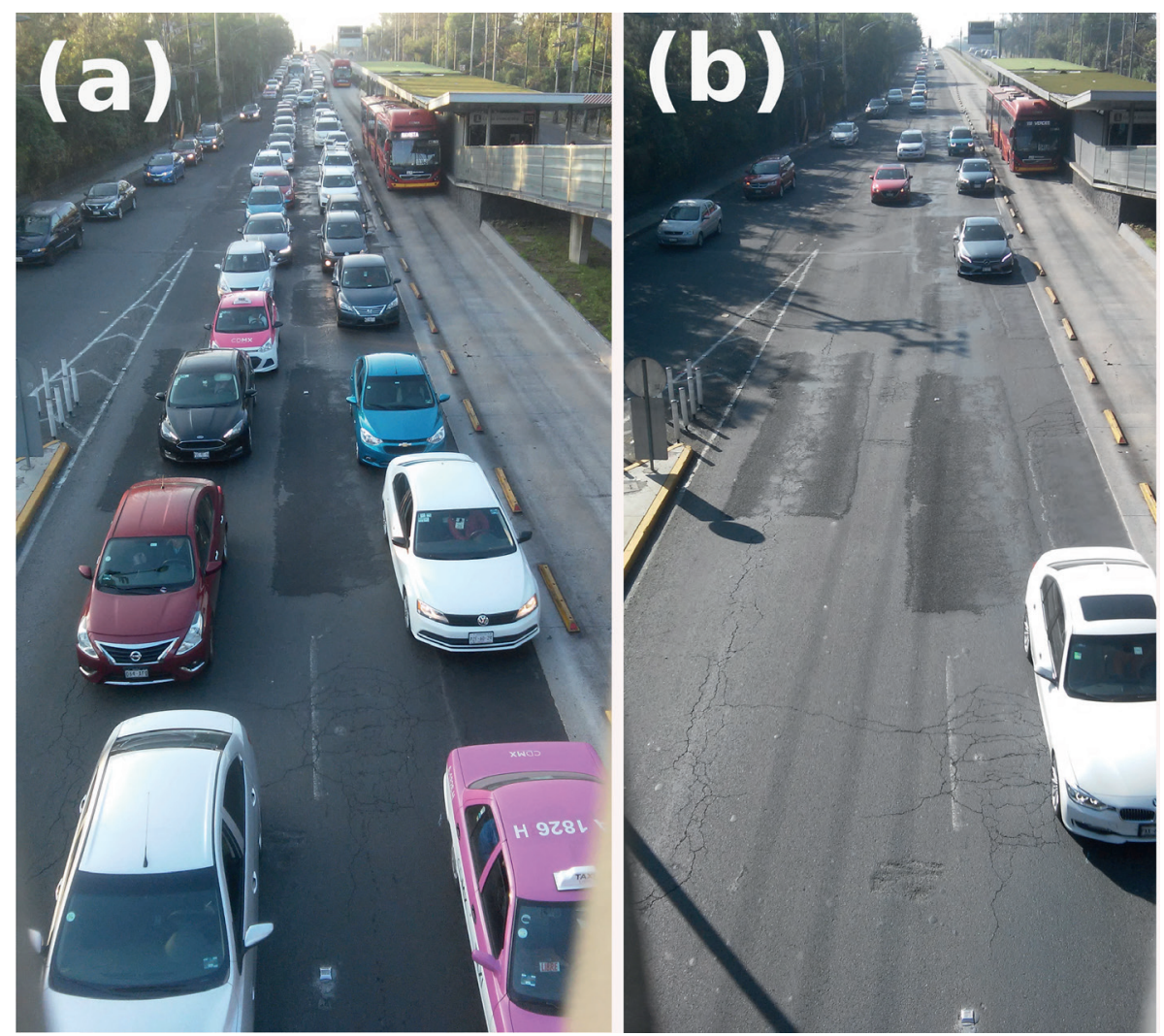

Figure 11 Insurgentes Sur, picture taken at point 2 of Figure 1, (a) at 7:26 am, (b) at 9:41 am.

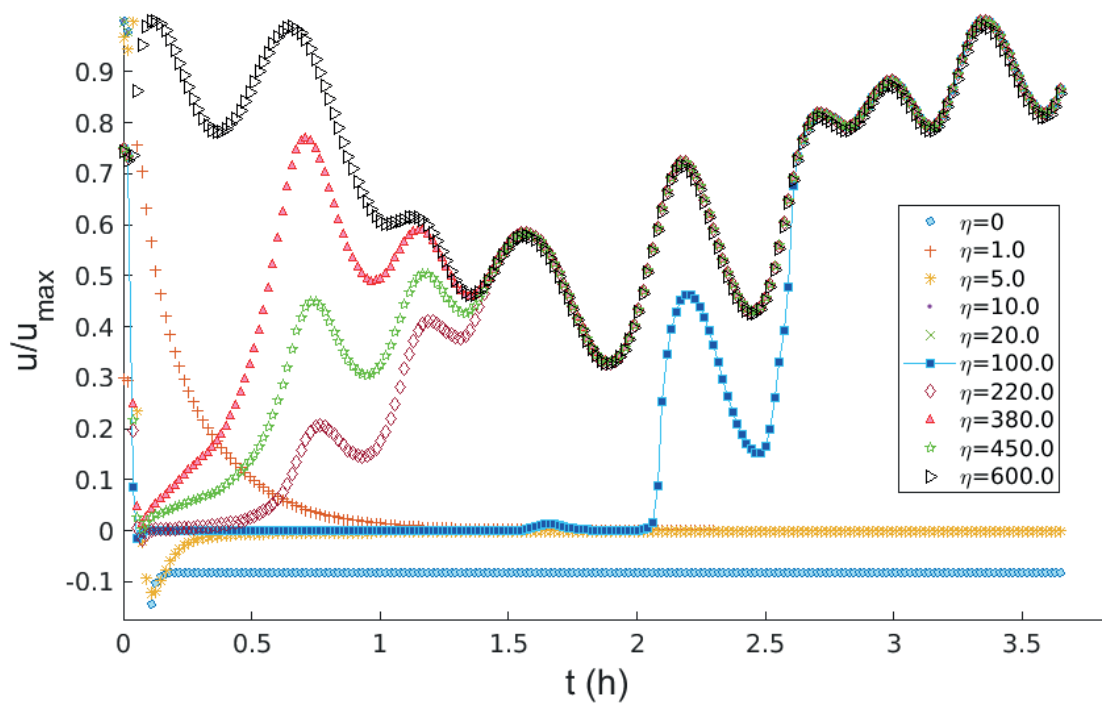

Figure 12 Normalized velocity time series for several values o $f$ the $\eta$ at the fixed point $x=500 \mathrm{~m}$, Insurgentes Sur case

there is a maximum of 750 veh $\mathrm{km}^{-1}$ (taking into account vehicles of $4 \mathrm{~m}$ in length and without a space between them).

The phase-space $(k, u)$ for the Insurgentes Sur case is shown in Figure 8. The least square regression (LSR) was used to calculate the coefficient of determination $\left(R^{2}\right)$ to determine how strong is the negative exponential relation (see Equation (6)) between $k$ and $u$. The relation found was the following: $k(u)=394 e^{-u / 39.04}$,

with $R^{2}=0.59$. It means that $c=39.04$. This value was utilized in the numerical simulation.

The function of the non-homogeneous continuity equation for the Insurgentes Sur case is shown in Figure 9. Except in the points where the sign changes, one can observe that this function is different from zero almost all the time. This function has more positive than negative 

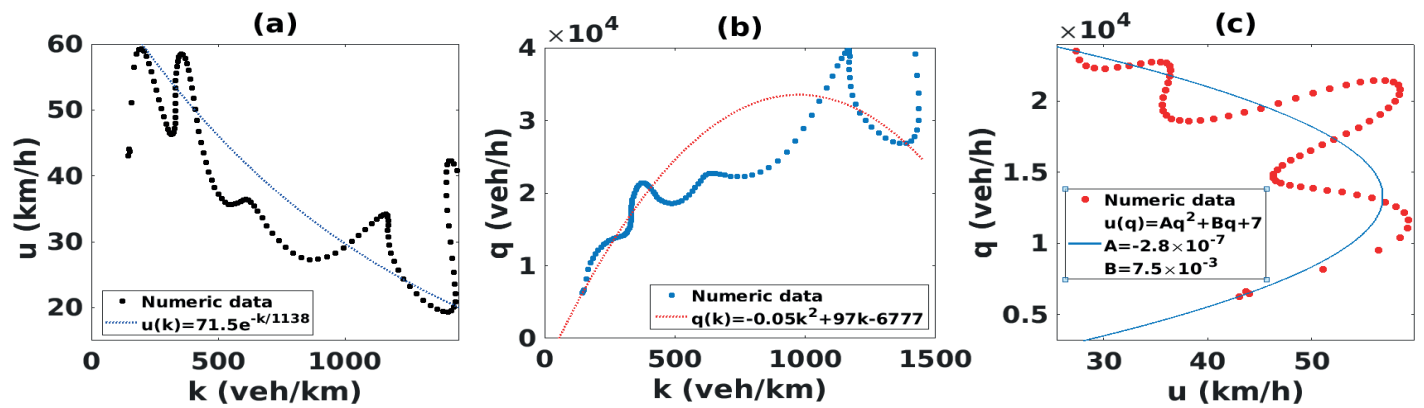

Figure 13 Fundamental diagrams for the Insurgentes Sur case, (a) u vs. $k$ with a negative exponential trend line, (b) $q$ vs. $k$ with a parabolic trend line, (c) $q$ vs. $u$ with a parabolic trend line

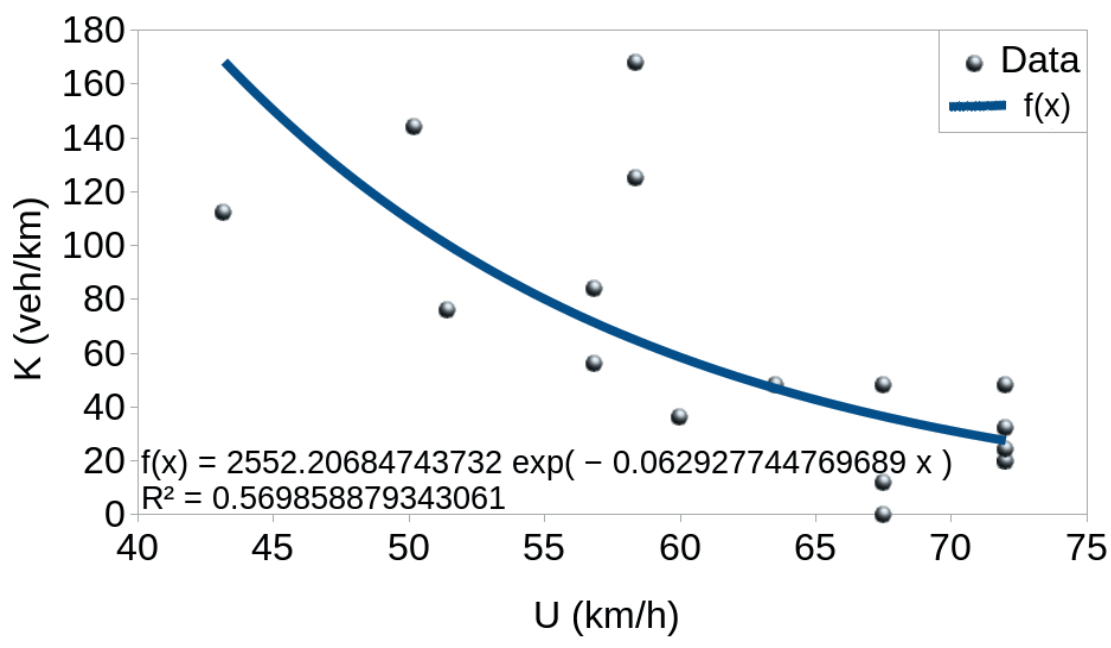

Figure 14 Phase portrait of the density and the velocity for the Mexico-Toluca case

values, which means that more vehicles came out than those that entered. So, there was a vehicle entry at an intermediate point on the avenue segment studied.

Velocity's 3D-graphs are shown in Figure 10 for three different values of $\eta$. If the viscosity is $\eta=100 \mathrm{~km} \mathrm{~h}^{-1}$, there are times and positions when the speed vanishes (see Figures 10(a) and 12); but if the viscosity is increasing towards $\eta=600 \mathrm{~km} \mathrm{~h}^{-1}$ the speed is always positive (see Figures 10(b) and 10(c)). Velocity increases (until the limit value) as the viscosity increases. In the Insurgentes Sur case, $u \in(0.65) \mathrm{km} \mathrm{h}^{-1}$ for $\eta>10 \mathrm{~km} \mathrm{~h}^{-1}$.

It is worth mentioning that the velocity diverges when the viscosity is small (or zero). Big negative and positive values of the velocity appear (more than $200 \mathrm{~km} / \mathrm{h}$ and close to $-800 \mathrm{~km} \mathrm{~h}^{-1}$ ). This case is numerically unstable. If the viscosity increases, the method becomes stable and the negative values disappear.

Figure 11 shows two moments at point 2 of Figure 1, (a) at 7:26 am and (b) at 9:41 am. An estimated viscosity value can be made observing each photograph. For example, a large number of vehicles are seen in Figure 11(a), the speed is low, so it can be related to Figure 10(a), the viscosity at that time would have a value $\eta=100 \mathrm{~km} \mathrm{~h}^{-1}$. Figure 11(b) shows fewer vehicles than in Figure 11(a); it means that the speed has increased along the road segment. Qualitatively, it can be related to Figure 10(c). In this case, it would be $\eta=600 \mathrm{~km} \mathrm{~h}^{-1}$. These facts are better observed in Figure 12. Time series of normalized velocity for different values of $\eta$ at a fixed point $x=500 \mathrm{~m}$ show the behavior of the velocity for the $\eta$ values.

For this position, the velocity is negative if $\eta=0$; it decreases to zero if $1 \leq \eta \leq 100 \mathrm{~km} \mathrm{~h}^{-1}$. When $t=2, u \neq 0$ for $\eta=100 \mathrm{~km} \mathrm{~h}^{-1}$. From the value $t=1.5 \mathrm{~h}^{-1}$, the speed is the same for $\eta>200 \mathrm{~km} \mathrm{~h}^{-1}$. The fundamental diagrams are shown in Figure 13. In all the cases, curves superimposed on the numerical data show a trend of said data. For the space phase $u$ - $k$ (Figure 13a), a negative exponential was assigned. Parabolic curves, whose equations are shown in the Figure 13, were superimposed on spaces $q-k$ and $q-u$ (Figures 13(b) and 13(c) respectively).

\subsection{Numerical results for Mexico-Toluca free road}

Mexico-Toluca freeway is a 2-lane road for all the kinds of transport vehicles. The phase-space $(k, u)$ is shown in Figure 14. The LSR shows thatthe determination coefficient for this case is $R^{2}=0.57$, which is very similar to the previous case. The negative exponential relation (Equation (6)) between $k$ and $u$ is:

$k(u)=2552 e^{-u / 15.89}$. 


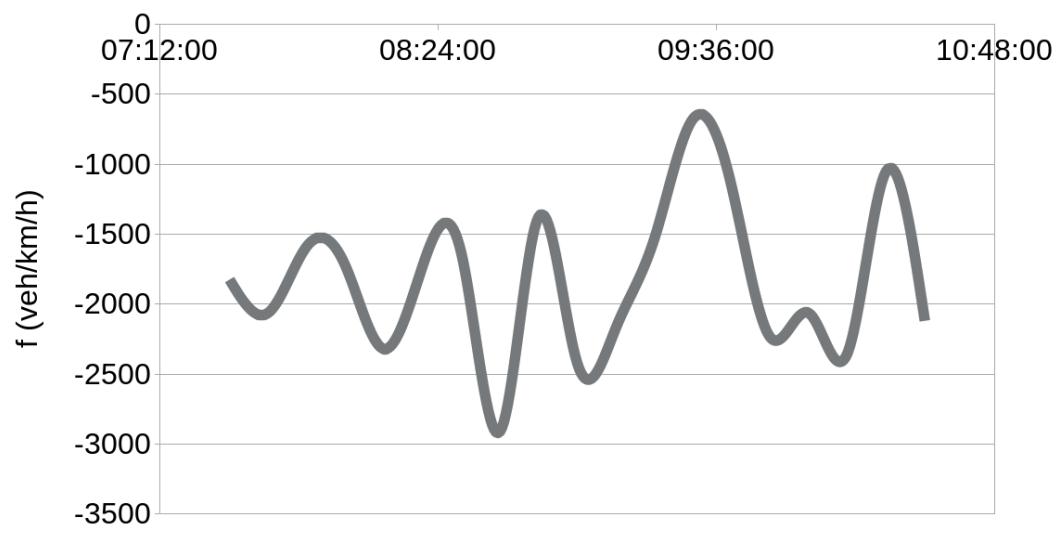

$\mathrm{t}(\mathrm{h})$

Figure 15 Function of the continuity equation for the Mexico-Toluca road

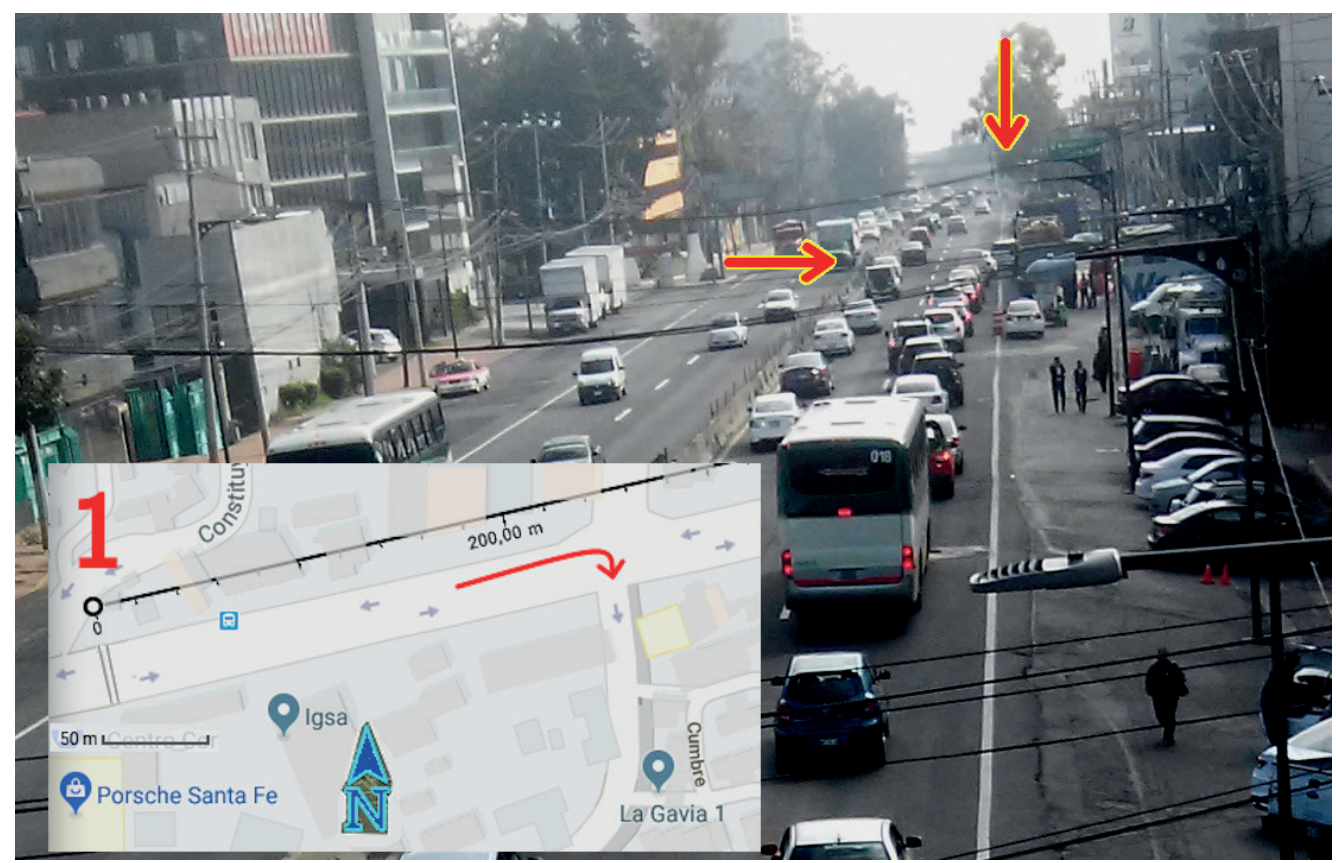

Figure 16 Cars are going out of the road to study at an intermediate point, a close-up of Figure 4 is added to the lower-left corner of the picture to locate the vehicle exit from a map.

It means that $c=15.89$. This value was utilized in the numerical simulation.

Function of the non-homogeneous continuity equation for the Mexico-Toluca case is shown in Figure 15. One can observe this function is different from zero all time. In fact, $f$ takes negative values. One can interpret this result like more vehicles to come in the road than those that leave the road. This interpretation is accurate, to many vehicles go out for the street ahead of point 1 (see Figure 16).

Figure 17 shows velocity 3D-graphs for three different values of $\eta$. Notably, if the viscosity is small, the velocity has non-realistic values. Negative velocities can appear in the model results. Physically, it implies a back movement, but a car does not move to $1000 \mathrm{~km} \mathrm{~h}^{-1}$ in reverse. This case is numerically unstable. However, if the viscosity increases, the velocity takes values ranging from zero to $75 \mathrm{~km} \mathrm{~h}^{-1}$.

When the viscosity value is $20 \mathrm{~km} \mathrm{~h}^{-1}$, the velocity drops to zero in practically the entire domain of the function (except at borders, see Figure 17(a)). When the viscosity increases again, the velocity increases too, but it does not exceed the limits of values at the boundaries (Figures 17(b) and 17(c)).

Figure 18 shows photographs taken at point 1 of Figure 4 at three different times. Many cars can be seen on the street in Figure 18 (a). This situation can be related to Figure 17 (b), that is, the viscosity value can be $\eta=20 \mathrm{~km} \mathrm{~h}^{-1}$. Figure 18 (b) show fewer cars than Figure 18 (a). Depending on the particular characteristics of the researchers' study, in this case, this picture can be associated with Figure 18 (b), i. e. the viscosity can take the value $\eta=100 \mathrm{~km} \mathrm{~h}^{-1}$. There are no cars in Figure 18 (c) in the studied lane, so, vehicles can move at any speed. In this case, the vehicle velocity can approach the velocity shown in Figure 17 (c).

The normalized velocity (see Figure 19) shows that several values for viscosity (not necessarily the maximum values) cause the velocity to drop to zero (for example, $\left.\eta=50 \mathrm{~km} \mathrm{~h}^{-1}\right)$. 

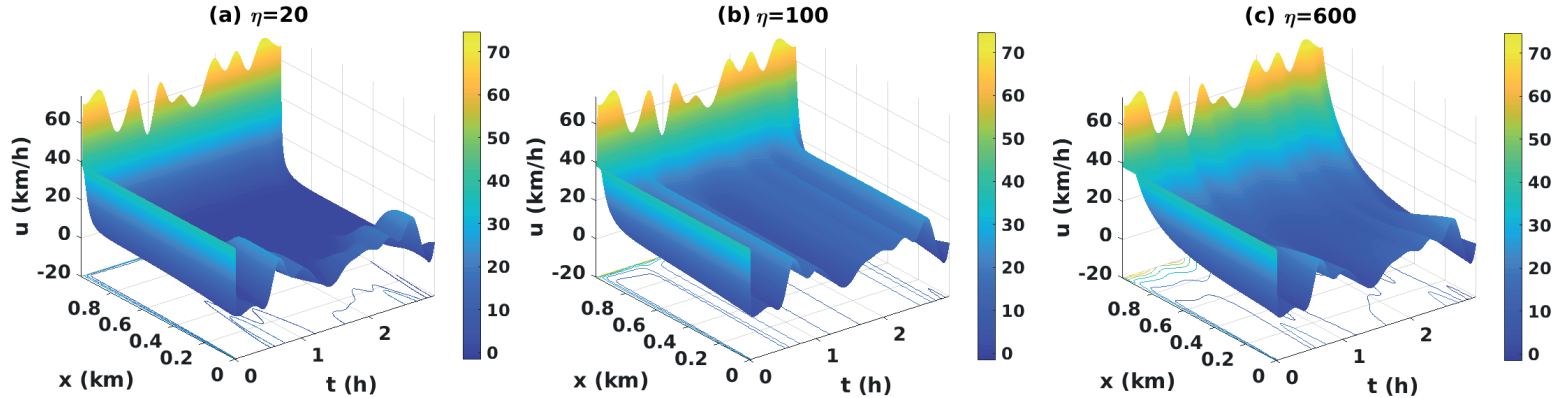

Figure 17 Velocity as a function of $x$ and $t$ for the Mexico-Toluca case, (a) $\eta=20 \mathrm{~km} \mathrm{~h}^{-1}$, (b) $\eta=100 \mathrm{~km} \mathrm{~h}^{-1}$, (c) $\eta=600 \mathrm{~km} \mathrm{~h}^{-1}$

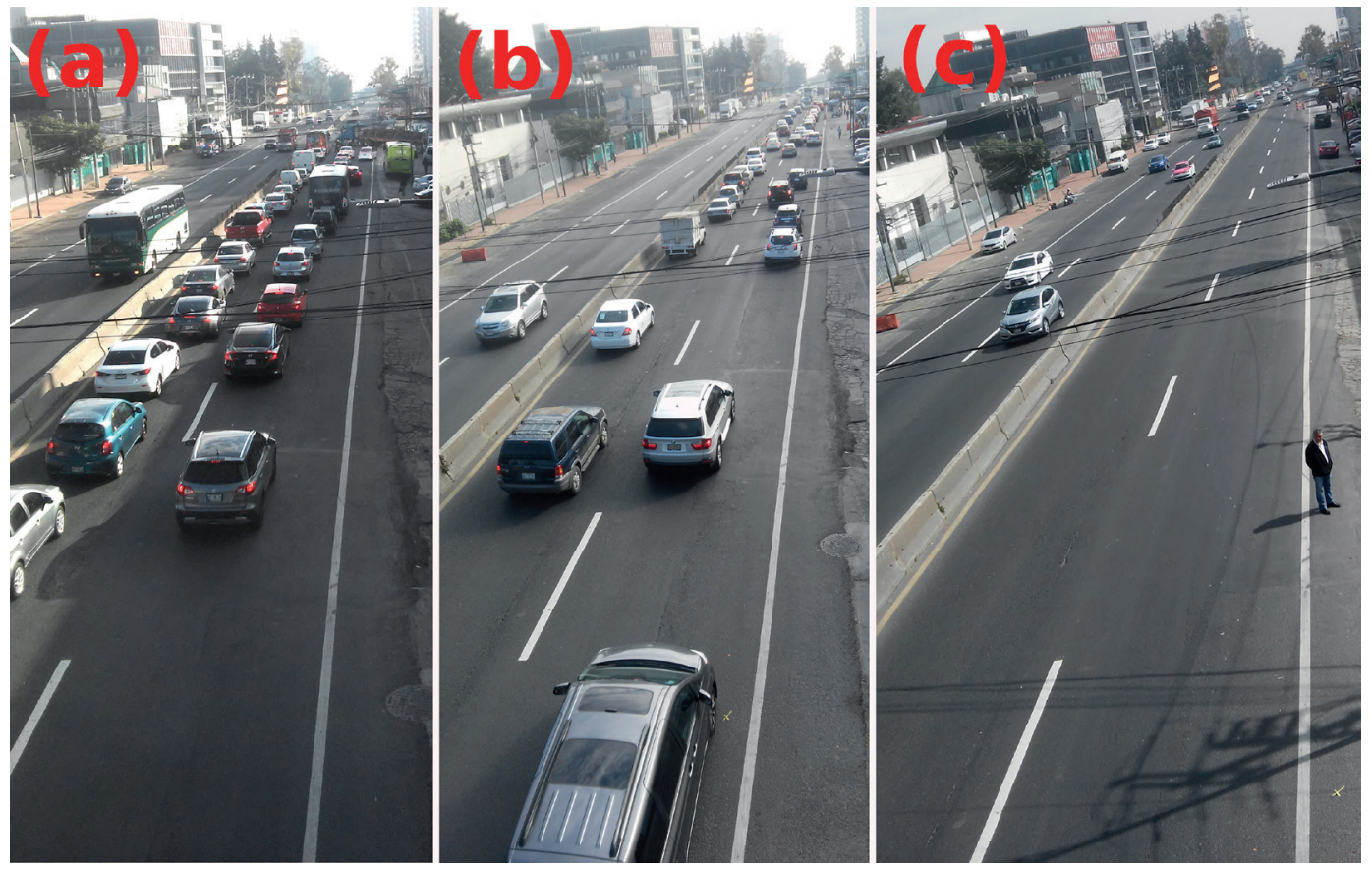

Figure 18 Mexico-Toluca, picture taken at point 1 of Figure 4, (a) at 8:32 am, (b) at 9:17 am,

(c) at 10:32 am, ictures: Authors

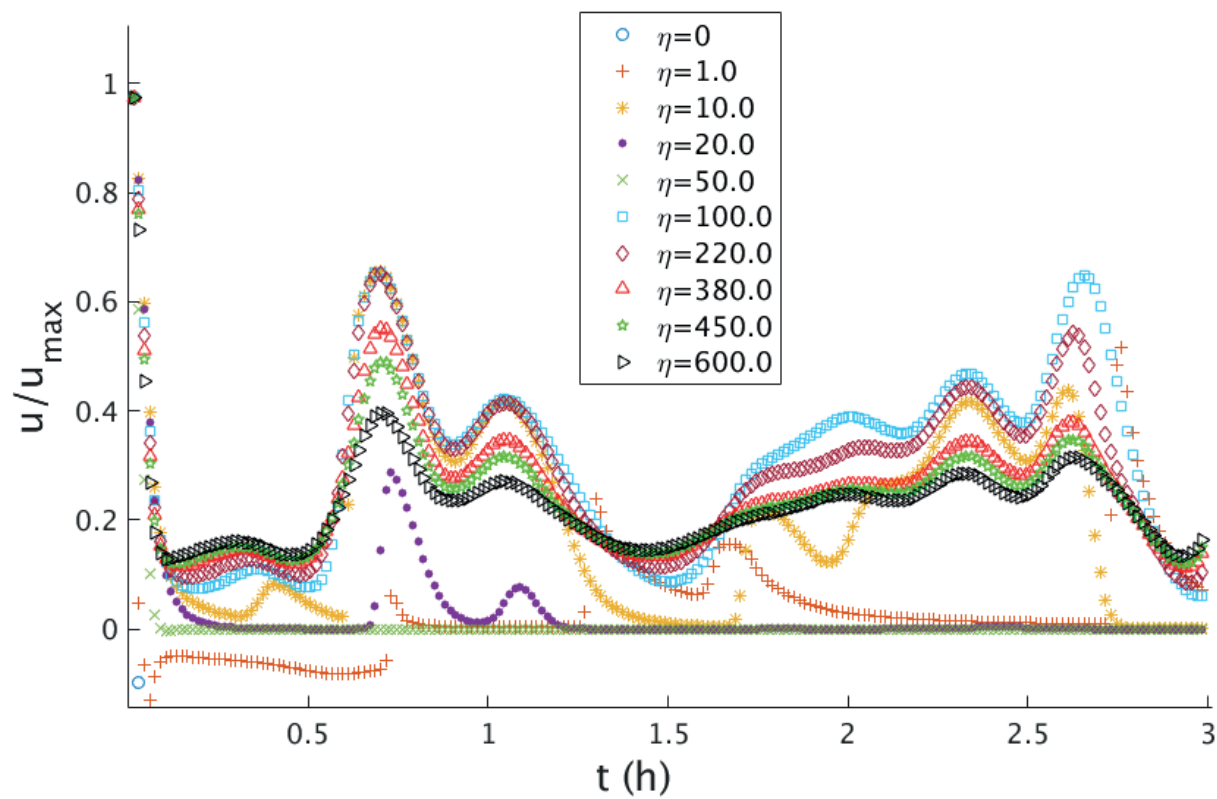

Figure 19 Normalized velocity time series for several values of the $\eta$, Mexico-Toluca case 
(a)

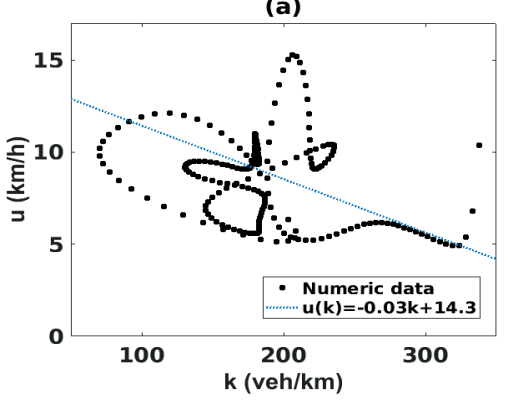

(b)

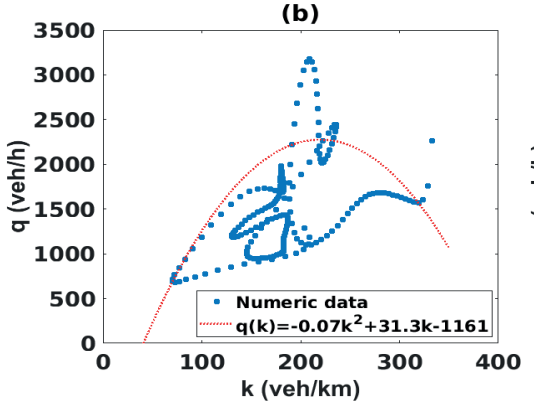

(c)

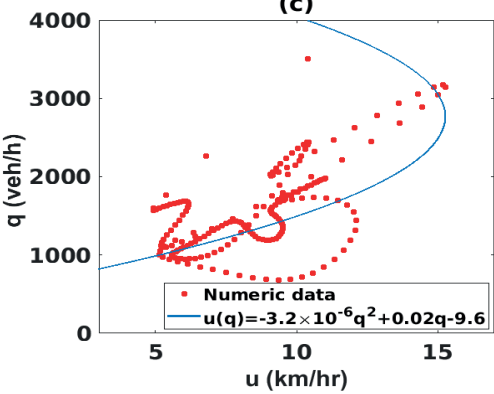

Figure 20 Fundamental diagrams for the Mexico-Toluca case, (a) u vs. $k$ with a negative slope straight line trend, (b) $q$ vs. $k$ with a parabolic trend line, (c) q vs. $u$ with a parabolic trend line

Expected trends in the fundamental diagrams in the case of the Mexico-Toluca freeway (Figure 20) are less clear than in the case of the Insurgentes Sur Ave. (Figure 12).

In this case, at the $u-k$ phase-space a line was inserted with a negative slope as a tendency of the inverse relationship of $u$ and $k$, Figure 20(a), instead of the negative exponential function that was used for the previous case.

A parabolic shape was imposed on the other two-phase spaces, as one can see in Figures 20(b) and 20(c).

\section{Summary}

A traffic study in two points of Mexico City is developed. Velocity, vehicular density, and vehicular flow were measured for approximately $3 \mathrm{~h}$ in sections of around $1 \mathrm{~km}$ long of two crowded streets. The aim of making these measurements was to get information on the initial and boundary conditions to perform the numerical simulation.

To estimate the parameter $c$, which was used as an input data in the numerical model, an analysis of the observed data was carried out following the Greenberg methodology. A qualitatively inverse relationship of $u$ and $k$ can be observed (Figure 2), as in literature [4, 39]. Nonetheless, this inverse relation is weakly correlated logarithmically.

Using the usual continuity equation (homogeneous equation), the model gave a constant value for the speed, at all the times and for practically the entire spatial domain, except in the vicinity of the border. Other numerical tests were made using the Neumann conditions [27-29]. The velocity was constant (these results are not shown in this paper), even on the borders.
The solutions of the inviscid model (or with small values of the viscosity) are numerically unstable. Nonrealistic values for vehicular density and speed are obtained. The solution gets expected values if the viscosity increases. The diffusion term ( i. e. the viscosity term) added to the motion equation makes the model to become stable [31], that is, the solutions take realistic or expected values.

Although the correlation between $k_{\text {measured }}$ and $u_{\text {measured }}$ is weak, the numerical results show expected values for $k$ and $u$. The phase-space or fundamental diagrams have expected trends.

The Courant number (see Figure 7) is less than 1 over all the solution integration's time. Thus, there is a convergence of the solution.

In the cases studied here, the viscosity value depends on the traffic time. The viscous term can be useful to define changes in the road parameters such as speed limits, reversible lanes, etc. to improve urban mobility.

One still needs to consider the effect of traffic lights, bottlenecks and block outs. In the future work, authors will consider the solution behavior of a fractional Greenberg model, which also has the effect of slowing down and with this, impairing in mobility.

\section{Acknowledgments}

To Dr. Gerardo Ruiz and MSc. Sergio Hernandez for the technical support and use of the Taller de Fluidos' computer servers in the Faculty of Sciences, UNAM. The authors thank SNI for support. E. J. Lopez-Sanchez thanks DGAPA-UNAM for the postdoctoral fellowship.

\section{References}

[1] GREENSHIELDS, D. B., BIDDINS, R. J., CHANNING, S. W., MILLER, H. H. A study in highway capacity. In: 14th Annual Meeting of the Highway Research Board: proceedings. Vol. 14. Highway Research Board, 1935. ISSN 0096-102, p. 448477.

[2] Lighthill, M. J., WhitMAN, G. B. On kinematic waves. II. A theory of traffic flow on long crowded roads. In: Royal Society of London: proceedings [online]. Vol. 229 A. 1955. ISSN 0080-4630, p. 317-345 Available from: https://royalsocietypublishing.org/doi/pdf/10.1098/rspa.1955.0089

[3] RICHARDS, P. I. Shock waves on the highway. Operations Research [online]. 1956, 4(1), p. 1-137. ISSN 0030-364X. Available from: https://doi.org/10.1287/opre.4.1.42 
[4] GREENBERG, H. An analysis of traffic flow. Operations Research [online]. 1959, 7(1), p. 79-85. ISSN 0030-364X. Available from: http://dx.doi.org/10.1287/opre.7.1.79

[5] NEWELL, G. F. Nonlinear effects in the dynamics of car following. Operations Research [online]. 1961, 9(2), p. 209-229. ISSN 0030-364X. Available from: https://doi.org/10.1287/opre.9.2.209

[6] PAVERI-FONTANA, S. L. On Boltzmann-like treatments for traffic flow: a critical review of the basic model and an alternative proposal for dilute traffic analysis. Transportation Research [online]. 1975, 9, p. 225-235. Available from: https://doi.org/10.1016/0041-1647(75)90063-5

[7] HELBING, D. Gas-kinetic derivation of Navier-Stokes-like traffic equations. Physical Review E [online]. 1996, 53(3), p. 2366-2381. ISSN 2470-0045. Available from: https://doi.org/10.1103/PhysRevE.53.2366

[8] PIPES, L. A. An operational analysis of traffic dynamics. Journal of Applied Physics [online]. 1953, 24, p. 274-281. ISSN 0021-8979. Available from: https://doi.org/10.1063/1.1721265

[9] PRIGOGINE, I., ANDREWS, F. C. A Boltzmann-like approach for traffic flow. Operations Research [online]. 1960, 8(6), p. 789-797. ISSN 0030-364X. Available from: https://doi.org/10.1287/opre.8.6.789

[10] DRAKE, J. S., SCHOFER, J. L., MAY, A. D. A statistical analysis of speed-density hypotheses. In: 45th Annual Meeting of the Highway Research Board: proceedings [online]. Vol. 154. Highway Research Board, 1967. ISSN 0096-102, p. 53-87. Available from: http://onlinepubs.trb.org/Onlinepubs/hrr/1967/154/154-004.pdf

[11] PAYNE, H. J. Models of freeway traffic and control. In: Mathematical Models of Public Systems. Vol. 1. La Jolla, USA: Simulation Councils, INC., 1971. p. 51-61.

[12] SMULDERS, S. Control of freeway traffic flow by variable speed signs. Transportation Research Part B: Methodological [online]. 1990, 24(2), p. 111-132. ISSN 0191-2615. Available from: https://doi.org/10.1016/0191-2615(90)90023-R

[13] DAGANZO, C. F. The cell transmission model: a dynamic representation of highway traffic consistent whit the hydrodynamic theory. Transportation Research Part B: Methodological [online]. 1994, 28(4), p. 269-287. ISSN 0191-2615. Available from: https://doi.org/10.1016/0191-2615(94)90002-7

[14] NELSON, P. Synchronized traffic flow from a modified Lighthill-Whitman model. Physical Review E [online]. 2000, 61(6), R6052. ISSN 2470-0045. Available from: https://doi.org/10.1103/PhysRevE.61.R6052

[15] ZHANG, H. M. A non-equilibrium traffic model devoid of gas-like behavior. Transportation Research Part B: Methodological [online]. 2002, 36(3), p. 275-290. ISSN 0191-2615. Available from: https://doi.org/10.1016/S01912615(00)00050-3

[16] VELASCO, R. M., MARQUEZ, W. Navier-stokes-like equations for traffic flow. Physical Review E [online]. 2005, 72, 046102. ISSN 2470-0045. Available from: https://doi.org/10.1103/PhysRevE.72.046102

[17] VAN WAGENINGEN-KESSELS, F., VAN LINT, H., VUIK, K., HOOGENDOORN, S. Genealogy of traffic flow models. EURO Journal on Transportation and Logistics [online]. 2015, 4, p. 445-473. ISSN 2192-4376, eISSN $2192-4384$. Available from: https://doi.org/10.1007/s13676-014-0045-5

[18] Origin destination survey of households in the Metropolitan Area of the Valley of Mexico / Encuesta origen destino en hogares de la Zona Metropolitana Valle de Mexico (in Spanish) - Inegi and Cdmx-Gov [online] [accessed 2019-10-02]. Available from: https://www.inegi.org.mx/contenidos/programas/eod/2017/doc/resultados_eod_2017.pdf

[19] ASUAD, N. E. The main challenges of the Mexico City conurbation and metropolitan transportation / Principales retos de la conurbacion de la Ciudad de Mexico y el transporte metropolitano (in Spanish) [online] [accessed 2019-04-10]. Available from: http://www.economia.unam.mx/cedrus/descargas/Retos\%20transporte\%20ZMCM.pdf

[20] MUNOZ, J. C., BATARCE, M., TORRES, I. ). Comparison of the level of public transport service in six Latin American cities / Comparacion del nivel de servicio del transporte publico en seis ciudades latinoamericanas (in Spanish). In: XVI Congreso Chileno de Ingenieria de Transporte: proceedings [online]. Vol. 18. 2013. p. 10-16. Available from: https://auroradechile.uchile.cl/index.php/CIT/article/view/28452/30173

[21] Inegi [online] [accessed 2019-11-25] Available from: https://www.inegi.org.mx

[22] MIRAlles-GUASH, C., CEBOlladA, A. Mobility and transportation. Political options for the city / Movilidad $y$ transporte. Opciones politicas para la ciudad (in Spanish) [online]. Madrid: Laboratorio de Alternativas, 2003. ISBN 84-96204-28-6. Available from: https://www.fundacionalternativas.org/public/storage/laboratorio_documentos_ archivos/xmlimport-GVOoD4.pdf

[23] HELBING, D., HENNECKE, A., TREIBER, M., SHVETSOV, V. Master: macroscopic traffic simulation based on a gaskinetic, non-local traffic model. Transportation Research Part B: Methodological [online]. 2001, 35, p. $183-211$. ISSN 0191-2615. Available from: https://doi.org/10.1016/S0191-2615(99)00047-8

[24] DELGADO, J., SAAVEDRA, P., VELASCO, R. M. Modeling of traffic flow problems / Modelacion de problemas de flujo vehicular (in Spanish) [online]. Iztapalapa, Mexico: CBI UAM, 2012. Available from: https://www.academia. edu/27515488/Modelaci\%C3\%B3n_de_problemas_de_flujo_vehicular[25] FANG, J., YE, H., EASA, S. M. Modified traffic flow model with connected vehicle microscopic data for proactive variable speed limit control. Journal of Advanced Transportation [online]. 2019, 8151582, p. 1-11. ISSN 0197-6729. Available from: https://doi.org/10.1155/2019/8151582

[26] GOMEZ-HERNANDEZ, E. Development of a vehicle simulation model to improve traffic light synchronization/ Desarrollo de un modelo de simulacion vehicular para la mejora en la sincronizacion de semaforos (in 
Spanish). PhD thesis. Puebla, Mexico: INAOE, 2009. Available from: https://inaoe.repositorioinstitucional.mx/jspui/ bitstream/1009/379/1/GomezHE.pdf

[27] ASMAR, N. H. Partial differential equations with Fourier series and boundary value problems. 2. Ed. USA: Pearson: Prentice-Hall, 2005. ISBN 0-13-148096-0.

[28] WEBER, H. J., ARFKEN, G. B. Essential mathematical methods for physicists. USA: Academic Press, 2003. ISBN 0-12059877-9.

[29] BOAS, M. L. Mathematical methods in the physical sciences. 3. ed. USA: John Wiley \& Sons., 2005. ISBN 978-0-47119826-0.

[30] GUYON, E., HULIN, J.-P., PETIT, L. Hidrodynamique physique. Paris: EDP Sciences, CNRS Ed., 2001. ISBN 2-86883502-3.

[31] TREIBER, M, A. KESTING, A. Traffic flow dynamics. data, models and simulation. Berlin Heidelberg: Springer-Verlag, 2013. ISBN 978-3-642-32460-4.

[32] BURDEN, R. L., FAIRES, J. D. Numerical analysis. 9. ed. USA: Cengage Learning, 2011. ISBN-13: 978-0-538-73351-9.

[33] MATTHEWS, J. H., FINK, K. D. Numerical methods: using Matlab. 3. edition. USA: Prentice-Hall, 1999. ISBN-13: 978-0132700429.

[34] ESI-OpenCFD. OpenFOAM. The open-source CFD toolbox. Programmer's guide. Version 3.0.1. [online] [accessed 201912-14]. Available from: http://foam.sourceforge.net/docs/Guides-a4/ProgrammersGuide.pdf

[35] KESSELS. F. Traffic flow modelling. Introduction to traffic flow theory through a genealogy of models. Cham, Switzerland: Springer, 2019. ISBN 978-3-319-78695-7.

[36] SMALL, K. A., VERHOEF, E. T. The economics of urban transportation. 2. ed. New York, USA: Taylor \& Francis and Routledge, 2007. ISBN-13: 978-0415285155.

[37] KERNER, B. S., KONHAUSER, P. Structure and parameters of clusters in traffic flow. Physical Review E. 1994, 50(1), p. 54-83. ISSN 2470-0045.

[38] DELGADO, J. SAAVEDRA, P. Global bifurcation diagram for the Kerner and Konhauser traffic flow model. International Journal of Bifurcation and Chaos [online]. 2015, 25(5), 1550064. ISSN 0218-1274. Available from: https://doi.org/10.1142/S0218127415500649

[39] HABERMAN, R. Mathematical models. Philadelphia, USA: Society for Industrial and Applied Mathematics, 1998. ISBN 0-89871408-7. 